\title{
Capitalismo, esquizofrenia e raça O negro e o pensamento negro na modernidade ocidental
}

\author{
Ingrid Robyn \\ Universidade de Nebraska-Lincoln, Nebraska, EUA
}

Mbembe, Achille. Crítica da razão negra. 1. ed. Lisboa: Antígona, 2014. Tradução de Marta Lança.

Crítica da razão negra, de Achille Mbembe (original em francês pela editora La Découverte, 2013), é um desses livros que nasceu já clássico: clássico não no sentido de antigo, ou imune à passagem do tempo, mas no sentido borgeano de ter sido escolhido por uma comunidade de leitores como leitura obrigatória. E o livro é, de fato, leitura obrigatória não apenas para aqueles que se interessam pela questáo do "negro", mas para todos aqueles que, de alguma forma, se interessam pela relação entre raça e modernidade, ou posto de outra maneira: raça, Estado e mercado. Porque o que o autor denomina devir-negro do mundo é, concretamente, uma teoria explicativa das rela-

\footnotetext{
1 "Nègre" no original, "black" na tradução ao inglês. Como veremos adiante, Mbembe analisa a categoria "negro" como uma construção histórica de longa duração que não se refere apenas aos sujeitos africanos e afrodescendentes, mas ao contrário se constrói como sinônimo de uma outredade absoluta; trata-se, portanto, de uma "ficção útil" que ultrapassa a questão da cor da pele, a origem ou a localização geográfica do sujeito negro.
}

çôes entre o pensamento racial no mundo ocidental e a emergência da modernidade em sua relação intrínseca com o desenvolvimento do Estado moderno e do capitalismo, sobretudo da chamada acumulação primitiva do capital (que, diga-se de passagem, tanto Mbembe como a teórica italiana Silvia Federici náo veem como uma etapa superada do desenvolvimento do capitalismo, e sim como algo ainda em curso). Situando-se entre a filosofia, a história e a crítica, Critica da razão negra é, ao mesmo tempo, uma abrangente e provocadora reflexão sobre os conceitos de "raça", "negro" e "África" no ocidente, e um panorama histórico das relações raciais no mundo ocidental entre os séculos XV e XXI. Ao mesmo tempo que analisa os processos históricos dos quais derivam estes conceitos, Mbembe também nos oferece um recorrido do que eu chamaria "pensamento negro" - a sua "razão negra" —, dialogando criticamente com uma série de filósofos, teóricos e escritores negros que se debruçaram sobre a sua condição e refletiram sobre as possibilidades de emancipação do negro no mundo ocidental; uma tradiçáo cujo ponto alto o autor localiza entre as décadas de vinte e setenta do século XX, mas

DOI - http://dx.doi.org/10.1590/2237-101X01803612

Resenha recebida em 5 de junho de 2017 e aprovada para publicação em 21 de agosto de 2017.

* Professora do Departamento de Línguas e Literaturas Modernas/Instituto de Estudos Étnicos. Universidade de Nebraska-Lincoln. E-mail: irobyn2@unl.edu. 
de cuja ideias ele se apropria para pensar o século XXI.

Apesar de que percorre um longo caminho histórico, a maior parte do livro se concentra em dois momentos históricos especialmente paradigmáticos da história das relaçôes entre Europa e África, assim como a construção dos conceitos de "negro" e "raça": o pensamento ilustrado do século XVIII francês e o colonialismo europeu sobre o continente africano no século XIX. Se bem faz remontar o termo "negro" ao século XVI, e conceda especial atenção à maneira como esta categoria opera nas Américas francesa e inglesa, é durante o iluminismo e o neocolonialismo europeus que Mbembe localiza o ponto nodal da construçáo do negro como sujeito racializado no Ocidente e, como tal, contraponto à humanidade encarnada pelo "branco":

o Negro e a raça têm significado, para os imaginários das sociedades europeias, a mesma coisa. (...) a sua aparição no saber e no discurso modernos sobre o homem (e, por consequência, sobre o humanismo e a Humanidade) foi, se não simultâneo, pelos menos paralelo; e, desde o início do século XVIII, constitui, no conjunto, o subsolo (inconfessado e muitas vezes negado), ou melhor, o núcleo complexo a partir do qual o projeto moderno de conhecimento - mas também de governação - se difundiu. (p. 10)

Antes de entrar a fundo no conteúdo do texto, no entanto, proponho uma pergunta: por que a tradução portuguesa do livro saiu três anos antes da sua tradução ao inglês, quando o mercado de editoras acadêmicas nos Estados Unidos - para ficar apenas com os Estados Unidos — é reconhecidamente mais ativo e mais lucrativo que o mercado editorial português tomado em seu conjunto?

A pergunta permite um sem-fim de hipóteses. Uma hipótese seria a de que foram os portugueses os primeiros europeus a ocupar as costas africanas e estabelecer o tráfico de escravos daquele continente, para o resto do mundo. A teoria, no entanto, é preguiçosa: sabemos do papel de companhias inglesas no tráfico de escravos de origem africana e, mais importante, do papel preponderante das colônias da América do Norte no que diz respeito à construção da categoria "negro". Além disso, tal hipótese apelaria ao nacionalismo português, algo do que o livro de Mbembe se afasta de forma notável.

Outra hipótese seria o interesse que o livro poderia suscitar em outros países de língua portuguesa, sobretudo as ex-colônias portuguesas na África e o Brasil. Mais condizente, esta hipótese não explica o outro lado da história: o fato de que o livro tenha demorado tanto em publicar-se em língua inglesa, quanto Mbembe na verdade confere certo protagonismo à Inglaterra e aos Estados Unidos tanto no que diz respeito ao tráfico negreiro e à escravidão como à construção das fabulações responsáveis pelo surgimento da figura do negro, e que em última instância determinariam os rumos da ideologia racial na modernidade.

Uma possível resposta encontra-se, talvez, na tese central que Mbembe desenvolve 
ao longo deste livro, e que encontra particular resistência no mundo anglo-saxão: a ideia de que o liberalismo - tanto econômico, como político - não é incompatível com a escravidão e o racismo; ao contrário, é o liberalismo que cria o negro e a noção de "raça", indissociável desta figura. Para Mbembe, ao mesmo tempo que o Estado moderno surge com e para o mercado global — é a máquina de guerra do Estado moderno que permite a empresa colonial, isto é, a escravidão em massa, o sistema de plantação e a acumulação primitiva de capital —, o liberalismo é a ideologia que justifica esta operação. Obviamente, Mbembe diferencia os processos históricos e ideologias específicos que distinguem o colonialismo dos séculos XV-XVIII, daqueles que irão caracterizar o século XIX e boa parte do século XX. No entanto, o autor não observa uma real ruptura entre esses dois tipos de colonialismos — e capitalismos - no que diz respeito à questáo do negro. Ao contrário, é o surgimento da noção de humanidade, no esteio do iluminismo e o liberalismo, o que garante a definitiva separação desta entre "brancos" — sinônimo de "homem", neste contexto — e "negros" vistos como uma outredade absoluta, como espécie de semi-homens cuja diferença radical frente ao "homem branco" justificaria a empresa colonizadora. Nos termos de Walter Migonolo, seria no século XVIII que se processa a separação dos homens entre $h u$ manitas e anthropos.

É esta a tese que o autor desenvolve nos três primeiros capítulos do livro, "A questão da raça", "O poço da alucinação" e "Diferença e autodeterminação". Seu ponto de partida, o questionamento das categorias "negro" e "África", e com elas, da noção de "raça”. Para Mbembe, o negro é uma ficção, um conjunto de fabulaçóes elaboradas no esteio do capitalismo mercantil e do estabelecimento do sistema de plantação. A criação da categoria "negro", à qual logo se vincularia a noção de "raça”, teria por finalidade estabelecer uma diferença radical, entendida como insuperável, entre a humanidade europeia e esse outro, o negro, sobre o qual se projetam todo tipo de medos e ansiedades. Esse outro, prossegue Mbembe, não seria homem no sentido pleno da palavra, mas sim objeto: pré-humano, vivendo em estado primitivo, incapaz de autogovernar-se, o negro seria então reduzido à condição de escravo - mercadoria e trabalho - e a empresa colonial justificada como obra "civilizatória" e inclusive "humanitária"; algo que, segundo o autor, continuaria informando o neoliberalismo do século XXI e os processos de globalização.

Junto com as categorias "negro" e "raça", surge a "África”, terra desconhecida e que não se quer conhecer, sobre as quais se projetariam também uma série de fabulaçóes. A partir de então, negro e África passariam a ser diretamente associados: o colonialismo e o desenvolvimento do capitalismo dariam lugar, ao mesmo tempo, a uma territorialização da raça e racialização do espaço. Essa associação sine qua non entre negro e África é algo que os próprios sujeitos negros abraçariam em seus primeiros intentos de emancipação, reclamando sua "africanidade essencial" como parte de sua identidade, e canibalizando assim o discurso europeu. 
Outro aspecto fundamental destes capítulos são as íntimas relações que se estabelecem entre o Estado moderno, o mercado e o racismo. Para Mbembe, o Estado moderno surge como instrumento do mercado e produto da razão mercantilista, a partir dos quais não apenas se estabelece uma partilha do mundo, mas uma partilha na qual a raça ocupa um papel central. Se o principal objetivo da lei e da burocracia é a coerção e controle dos corpos, e o medo é o principal instrumento do Estado - como já afirmara Michel Foucault — , é sobre o negro que irá se projetar este medo, e portanto sobre seu corpo que se exercerá o controle do Estado. Além do mais, o surgimento do direito moderno, na Europa, implicou entender tudo o que está além dela — homens incluídos - como ao mesmo tempo além e aquém da lei. Para Mbembe, o Estado moderno e o liberalismo surgem, então, como instrumentos biopolíticos por excelência que irão permitir e justificar a escravização do negro - entendido como ameaça, como conjunto de fabulaçóes e de disparates que por sua vez disparam afetos —, o estabelecimento do sistema de plantação e, com isto, de um mercado global:

No ensaio La Naissance de la biopolitique, Foucault defende que, na origem, o liberalismo "implica intrinsecamente uma relação de produção/destruição [com] a liberdade”. Esquece-se de explicar que, historicamente, a escravatura dos Negros representa o ponto culminante desta destruição da liberdade. Segundo Foucault, o paradoxo do liberalismo é que "é necessário, por um lado, produzir a liberdade, mas esse próprio gesto implica que, do outro lado, se estabeleçam limitaçôes, controles, coerçôes, obrigaçôes apoiadas em ameaças, etc." A produção da liberdade tem portanto um custo cujo princípio de cálculo é, acrescenta Foucault, a segurança e a protecção. Por outras palavras, a economia do poder característica do liberalismo e da democracia do mesmo tipo assenta no jogo cerrado da liberdade, da segurança e da protecção contra a omnipresença da ameaça, do risco e do perigo. (...) $\mathrm{O}$ escravo negro representa este perigo. (p. 143)

É neste sentido que o liberalismo e inclusive o discurso sobre direitos humanos solidificam o racismo. O liberalismo econômico tem por base o comércio de escravos, responsável pelo desenvolvimento do capitalismo e pelo que hoje chamamos globalização. Neste contexto, o negro ocupa o papel de mercadoria e de matéria energética: ele é, ao mesmo tempo, homem-mineral (não homem, natureza), homem-metal (escravo, instrumento de extração) e homem-moeda (produtor de mercadorias e mercadoria em si mesmo). Por sua vez, o liberalismo político e o discurso sobre os direitos humanos, herdeiro do iluminismo, utilizam a escravidão como metáfora da condição humana em seu conjunto, ao mesmo tempo que apagam a existência do racismo sob a bandeira da igualdade e da fraternidade: trata-se de um discurso universalizante que, por isso mesmo, é incapaz de dar conta da diferença histórica sobre a qual se fundam as catego- 
rias "negro" e "raça”. Ao contrário, sugere Mbembe, trata-se de reafirmá-las ante a suposta impossibilidade de conciliação entre a "raça branca", portadora de humanidade e cidadania plenas, e a "raça negra":

O direito é, portanto, neste caso, uma maneira de fundar juridicamente uma certa ideia de Humanidade enquanto estiver dividida entre uma raça de conquistadores e uma raça de servos. Só a raça de conquistadores é legítima para ter qualidade humana. A qualidade do ser humano não pode ser dada como conjunto a todos e, ainda que o fosse, não aboliria as diferenças. $^{2}$ (p. 111)

O século XIX concluiria o trabalho de exclusão a partir do qual a África e o negro se vêm separados da "história da civilização": sem lei e nem razão, a África e o negro deveriam ser paulatinamente "introduzidos" ao processo civilizatório sob a égide europeia. A noção de "decadência do ocidente", bastante popular nas primeiras décadas do século XX, e o exotismo com o qual se recobre o continente africano visto pela vanguarda europeia e também caribenha como portador de uma vitalidade perdida no velho continente — não fazem senão reafirmar esses discursos, ainda quando se buscava reivindicar o termo "ne-

\footnotetext{
${ }^{2}$ Mbembe se refere aqui ao direito moderno, e que continua informando tanto o funcionamento do Estado como o discurso sobre direitos humanos. Fundado numa noção universalizante de humanidade, o discurso sobre direitos humanos, de acordo com Mbembe, teria como resultado a obliteração da cisão fundamental que se estabelece a partir da própria criação da categoria "homem".
}

gro" como categoria de autodeterminação, e não mera projeção alheia.

Paralelamente à descrição dos processos históricos que discute, Mbembe vai deslindando o pensamento negro, a sua "crítica da razão negra”, à que irá se dedicar de maneira mais direta a partir do capítulo três. Durante os séculos XV-XVIII, o negro expressa uma espécie de cisão a partir do qual habita a si mesmo como um outro, expressando mesmo um desejo de ser outro - como já o havia sugerido Franz Fanon. Neste primeiro momento, o negro abraçaria os discursos e fabulaçóes que o constroem como tal e lhe retiram a sua humanidade, ao mesmo tempo que está obrigado a reconhecer sua condição humana. Mesmo com o fim do tráfico de escravos e os movimentos de emancipação do século XIX, afirma Mbembe, o pensamento negro reproduziria as três respostas elaboradas pelo Ocidente no que diz respeito ao "problema africano": a noção de que África representaria uma humanidade sem história, aquém da razão e da lei; a noção de que a diferença radical do negro é algo a emendar-se, para o qual se faria necessário administrar, ainda que de forma indireta, tanto os escravos libertos e seus descendentes como o continente africano como um todo; a ideia de que o negro deve assimilar-se ao projeto civilizatório europeu para tornar-se um ser humano e um cidadão.

Se nesse primeiro momento o negro experimentaria um processo de desapropriaçáo e de degradação, num segundo momento, o pensamento negro se caracterizaria pela vitimização. Para Mbembe, o pensamento negro do século XIX e inícios do século XX te- 
ria sido incapaz de escapar do universalismo e humanismo liberal-ilustrados, abraçando a noção de reabilitação como forma de afirmar a sua humanidade. Neste contexto, o pensamento negro náo nega, mas sim incorpora a noçấo de raça, fazendo dela fundamento para sua ideia de nação:

A reafirmação de uma identidade humana negada por outro participa, neste sentido, do discurso da refutação e da reabilitação. Mas se o discurso da reabilitação procura confirmar a co-pertença negra à Humanidade, não recusa, no entanto - exceto em raros casos —, a ficção de um sujeito de raça ou da raça em geral. $\mathrm{Na}$ realidade, abraça esta ficção. Isto é tâo válido para a negritude como para as variantes do pan-africanismo. (p. 158)

Além disso, e como vítima, o negro passaria a ver a sua própria história como série de fatalidades causadas por um inimigo externo, planteando a necessidade de superar o seu passado e inclusive esquecê-lo, para poder gerar uma possibilidade de futuro.

É este, em grande medida, o tema do capítulo quatro deste livro, "O pequeno segredo", dedicado à questão da memória e ao que o autor denomina "modos de inserção da colônia no texto negro". Como origem da cisão fundamental a partir da qual emerge o negro, locus de uma perda originária, a colônia será contraditoriamente algo comemorado e relegado ao esquecimento. A colônia, afirma Mbeme, se apresenta para o negro ao mesmo tempo como violência e como espécie de espelho no qual se reconhece a si mes- mo. Neste sentido, a memória da colônia se apresentará como ponto fulcral da literatura negra, e com ela, o problema do olhar: é o olhar do colonizador que cria o negro, um olhar que não vê mais além de um corpo sobre o qual projeta todo tipo de ansiedade sexual, e que se alimenta da sua própria ignorância:

África propriamente dita - à qual acrescentaria o Negro - só existe a partir do texto que a constrói como ficção do outro. (...) Por outras palavras, África só existe a partir de uma biblioteca colonial por todo o lado imiscuída e insinuada, até no discurso que pretende refutá-la, a ponto de, em matéria de identidade, tradição ou autenticidade, ser impossível, ou pelo menos difícil, distinguir o original da sua cópia e, até, do seu simulacro. (p. 166)

Outro aspecto que Mbembe associa à colônia é seu papel como produtora de desejos e alucinaçôes. A colônia, afirma ele, faz circular no continente africano toda uma série de mercadorias e bens simbólicos que excitam o desejo dos colonizados, que passam quase imediatamente a ser considerados signos de prestígio, status, classe etc. Nesse sentido, a colônia é, também, objeto de desejo. Sua memória, então, apresenta-se à literatura africana como algo que ultrapassa os limites daquilo que a linguagem pode expressar, mas também como inelidível.

O quinto capítulo de Crítica da razão negra, "Réquiem para o escravo", está dedicado quase exclusivamente à literatura negra. Neste capítulo, Mbembe se debruça sobre 
certos motivos correntes na literatura contemporânea, e que remetem à duplicidade de que nela se recobre a figura do negro: reverso da humanidade, mas incapaz de ignorar sua condição humana, o negro se identifica com seu duplo, a sua sombra, convertendo-se em espécie de fantasma, alienado do próprio corpo. Na realidade - e aqui Mbembe se afasta notavelmente do marxismo clássico —, dissociar-se do próprio corpo, metamorfosear-se, seria condiçáo fundamental para a emancipação do negro, uma vez que a operação básica do capitalismo racial consiste precisamente em converter o negro em corpo para o trabalho, isto é, em objeto.

O último capítulo do livro, "Clínica do sujeito", nos oferece um recorrido do pensamento negro no século XX, analisando criticamente diferentes propostas de emancipação que marcaram o período: especificamente, as de Marcus Garvey, Aimé Césaire, Franz Fanon e Nelson Mandela. Após comentar em detalhe cada um desses pensadores, Mbembe propóe dividir o pensamento negro contemporâneo em dois períodos: um primeiro no qual o desejo de autodeterminação passaria pela afirmação da diferença e celebraçáo da negritude, do qual o exemplo máximo seria Aimé Césaire; e um outro, o do século XXI, no qual se abraçaria o significante negro não como forma de autoafirmação ou autocompadecimento, mas sim para melhor livrar-se dele. Para Mbembe, o atual mundo globalizado requereria uma crítica radical da raça, tanto política como ética, a partir da qual seria possível passar de uma afirmaçáo da diferença para uma afirmação da comunidade humana. Valendo-se, sobretudo, de Fanon, e estendendo a questão do negro ao que o autor chama "novos condenados da terra", Mbembe afirma que qualquer projeto efetivamente emancipador, nos dias de hoje, requer que o negro abandone o papel de vítima, por um lado, e que os colonizadores assumam a sua responsabilidade, de outro. Trata-se, segundo ele, de insistir na lógica da justiça; algo que se observa em movimentos negros contemporâneos como Black Lives Matter: ${ }^{3}$

Enquanto persistir a ideia segundo a qual só se deve justiça aos seus e que existem raças e povos desiguais, e enquanto se continuar a fazer crer que a escravatura e o colonialismo foram grandes feitos da "civilização", a temática da reparação continuará a ser mobilizada pelas vítimas históricas da expansão e brutalidade europeia no mundo. Neste contexto, é necessária uma dupla abordagem. Por um lado, é preciso abandonar o estatuto de vítima. Por outro, é preciso romper com a "boa consciência" e a negação da responsabilidade. Será nesta dupla condição que é possível articular uma política e uma ética novas, baseadas na exigência de justiça. (p. 297)

Seria impossível dar conta aqui de toda a riqueza intelectual e gama de ideias que de-

\footnotetext{
${ }^{3}$ Refiro-me ao principal slogan do movimento BLM, "No justice, no peace!" (Sem justiça não há paz!), mas também ao fato de que o movimento rejeita a "boa consciência branca", que via de regra se limita a converter o negro em vítima e portanto reproduz a lógica paternalista a partir da qual operam as relações raciais.
} 
senvolve Achille Mbembe nesse livro. Para finalizar, ressaltaria a contribuição teórica que oferece o autor, que compartilha com Fanon a qualidade de náo poupar a sensibilidade do leitor. Claramente inspirado nas obras de teóricos como Gilles Deleuze e Michel Foucault, Crítica da razâo negra responde a esses teóricos apontando a centralidade do negro e da noçáo de raça para o desenvolvimento da modernidade. Ao mesmo tempo, Mbembe incorpora em sua escritura as contribuiçóes de toda uma série de teóricos negros - africanos, caribenhos e norte-americanos - e até mesmo de teóricos latino-americanos como Walter Mignolo. Trata-se portanto de um arcabouço teórico que apenas em aparência deriva direta ou exclusivamente da tradiçáo francesa. Ao demonstrar a relação inelidível entre o pensamento sobre raça no Ocidente, a constituição do Estado moderno e o mercado, Mbembe desloca o centro de preocupaçóes da crítica de esquerda europeia da história do capital e dos chamados direitos humanos para a questão da raça. Ao mesmo tempo, o autor denuncia também as contradiçôes do pensamento libertário e nacionalista negros, ressaltando suas dívidas para com a "razão branca" e insuficiências no que diz respeito a qualquer perspectiva de futuro. Por fim, apesar de enfocar-se na questáo do negro em sua relação com a África e o colonialismo europeu - o negro como homem de origem ou descendência africana - as teses desenvolvidas em Crítica da razão negra, como indica o próprio autor, referem-se antes ao que ele denomina um devir-negro do mundo; expressão que introduz a possibilidade de pensar outros sujeitos racializados - muçulmanos, por exemplo - como os "novos negros" do mundo contemporâneo, e que reforça a ideia de que a categoria negro não passa de uma ficção útil. Não humano ou sub-humano, e ainda, ameaça ao mundo dos "brancos" - o que equivale a dizer, à "humanidade" mesma - o negro é portanto passível de ser explorado, isolado do resto da "humanidade" e, inclusive, exterminado. Neste sentido, Crítica da razão negra oferece não apenas chaves fundamentais para pensar-se a experiência do outro na modernidade, mas também a sua emancipação; aspecto fundamental para o desenvolvimento da humanidade mesma.

\section{Como citar}

Mbembe, Achille. Crítica da razão negra. Lisboa: Antígona, 2014. Tradução de Marta Lança. 1. ed. Resenha de ROBYN, Ingrid. Capitalismo, esquizofrenia e raça. $\mathrm{O}$ negro e o pensamento negro na modernidade ocidental. Topoi. Revista de História, Rio de Janeiro, v. 18, n. 36, p. 696-703, set./dez. 2017. Disponível em: <www.revistatopoi.org >. 